\title{
PORTUGUÊS LÍNGUA ESTRANGEIRA: UM CARNAVAL NO WORLD CAFÉ
}

\author{
Portugués como lengua extranjera: un carnaval en el World Café
}

Débora Racy Soares ${ }^{1}$

Recibido 27/11/2019

Aceptado 30/01/2020

\begin{abstract}
RESUMO
A proposta deste artigo é apresentar uma experiência de ensino que utilizou a metodologia do World Café para fomentar a discussão e a reflexão sobre o Carnaval. Esta experiência foi desenvolvida na Universidade Federal de Lavras (UFLA), em Minas Gerais, no Brasil. Alunos da turma de Português Língua Estrangeira III produziram redações que foram reunidas na coletânea "Olhares Estrangeiros sobre o Carnaval Brasileiro" e publicadas no site da universidade.
\end{abstract}

Palavras-chave: World Café, Carnaval, UFLA, Olhares, PortuguêsLínguaEstrangeira.

\section{RESUMEN}

El propósito de este artículo es presentar una experiencia docente que utilizó la metodología del World Café para fomentar la discusión y la reflexión acerca del Carnaval. Este experimento fue desarrollado en la Universidad Federal de Lavras (UFLA) en Minas Gerais, Brasil. Los estudiantes del curso de portugués como lengua extranjera III produjeron ensayos que fueron reunidos en la colección "Miradas extranjeras acerca del carnaval brasileño" y publicados en el sitio web de la universidad.

Palabras clave: World Café, Carnaval, UFLA, Miradas, Portugués, Lengua Extranjera.

\begin{abstract}
The purpose of this article is to present a teaching experience that used the World Café methodology to encourage discussion and reflection on Carnival. This experience was developed at the Federal University of Lavras (UFLA) in Minas Gerais, Brazil. The students of the course of Portuguese as a foreign language III produced essays that were collected in the collection "Foreign glances about the Brazilian carnival" and published on the university's website.
\end{abstract}

Key words: World Café, Carnival, UFLA, Miradas, Portuguese, Foreign Language.

\section{World Café}

A proposta deste artigo é apresentar uma experiência de ensino que utilizou a metodologia do World Café para fomentar a discussão e a reflexão sobre a cultura brasileira, em especial, sobre um tópico específico: o Carnaval. Esta experiência foi desenvolvida com uma turma de Português Língua Estrangeira III, no segundo semestre de 2015, na Universidade Federal de Lavras (UFLA), em Minas Gerais, no Brasil. Oito alunos participaram das atividades que resultaram na publicação online de uma coletânea de redações.

O World Café pode ser definido como uma metodologia de conversa em grupo, que foi criada por Juanita Brown e David Isaacs (2005), em 1995, na Califórnia, Estados Unidos.

\footnotetext{
${ }^{1}$ Universidade Federal de Lavras (UFLA) - debora_racy@yahoo.com.br
} 


\section{ISSN 2707-1642}

$\mathrm{Na}$ atualidade, é muito difundida mundialmente, podendo ser utilizada com propósitos variados, já que seu fio condutor é a troca de ideias e experiências sobre um determinado assunto. O compartilhamento do conhecimento, de forma criativa, por meio do diálogo, através do World Café, pode ser utilizado também em aulas de Português Língua Estrangeira, com as devidas adaptações.

Embora tenha surgido em um contexto empresarial, sem preocupação pedagógica, esta metodologia pode ser muito útil na área educacional. Ao criar uma rede viva, colaborativa, de diálogos, ideias, soluções, mobiliza-se, neste Café, a inteligência coletiva para responder ou, pelo menos, tentar entender, questões de grande relevância para as organizações e as comunidades.

Assim posto, a circulação do conhecimento de um grupo específico, sobre um dado assunto, ganha espaço através dos princípios do World Café. O principal deles é a consciência do propósito, isto é, para que se possa atingir determinado objetivo é necessário estabelecer um motivo claro para o encontro. No caso específico desta experiência de ensino, o encontro aconteceu em uma sexta-feira, das 14:00 às 18:00 horas, mais precisamente no horário das aulas da disciplina de Português Língua Estrangeira III. O motivo: discutir sobre um tópico específico de cultura brasileira com o objetivo de se escrever redações sobre o tema. A discussão seria em grupo, em Português brasileiro, através da metodologia do World Café. Já as redações seriam produzidas individualmente, a partir dos desdobramentos do batepapo coletivo.

Participaram da discussão oito alunos, sendo sete falantes de espanhol como língua materna e um falante de árabe e de francês. O Português é a segunda língua da maioria dos alunos, à exceção de dois: um a aprendia como terceira língua, outro como quarta. Todos são alunos de pós-graduação (mestrado ou doutorado), regularmente matriculados em diferentes programas da UFLA.

Chegou-se ao tema da seguinte forma. Antes do World Café acontecer, a docente responsável pela disciplina fez, em conjunto com a turma, um levantamento de temas de interesse. Surgiram os seguintes assuntos: comida brasileira e/ou mineira, Carnaval, futebol, corrupção. Por votação, decidiu-se que o Carnaval seria o tema contemplado e, portanto, o assunto das redações. O grupo estava no Brasil há pouco mais de um ano e, portanto, tinha vivenciado a festa in loco, seja assistindo os festejos e os desfiles em Lavras ou em outras cidades, seja acompanhando a cobertura midiática, através de telejornais nacionais e estrangeiros.

É instigante analisar os temas de interesse dos discentes, à luz da ideia de cultura que se instaura em sala de aula de Português Língua Estrangeira. Voltar-se-á a essa questão, oportunamente, na seção seguinte "Carnaval no World Café". Por ora, vamos aos princípios que embasam o World Café.

Após determinado o motivo para o encontro, é fundamental criar um espaço acolhedor, receptivo, cuja atmosfera possa contribuir para propiciar o diálogo e a troca fecunda de ideias sobre o assunto estabelecido a priori. O espaço utilizado foi a sala de aula de Português Língua Estrangeira. Pão de queijo e cafezinho foram oferecidos como forma de tornar o ambiente mais agradável, remetendo ao clima de uma cafeteria. Em seguida, é preciso explorar questões relevantes. $\mathrm{O}$ docente deve elaborar algumas perguntas norteadoras, que possam não só fomentar a discussão, mas também conduzir a descobertas interessantes. "O que é Carnaval para vocês?"- foi a questão inaugural, seguida da: "Aideia que vocês têm sobre o Carnaval mudou depois que vocês passaram a viver no Brasil?" Como as respostas foram afirmativas, indagou-se sobre o que teria mudado e como eles percebiam o Carnaval naquele momento, já vivendo no país. "Há Carnaval nos países de vocês ou alguma 
festa parecida?"- foi a pergunta seguinte, acompanhada pela solicitação de explicação sobre as formas de se comemorar o Carnaval e/ou a festa mencionada.

Em momento adequado, a docente abordou, de forma breve e oral, a história do Carnaval, explicando que se tratava de uma data móvel, cuja origem remeteria ao carne vale (pelo latim tardio) ou "adeus à carne". No final da aula os alunos receberam um texto que abordava a história do Carnaval entre os antigos egípcios (festas de Ísis), gregos (bacanais) e romanos (saturnais). Segundo os estudiosos, o "navio de Ísis" (Navigium Isidis) teria sido a possível origem dos carros alegóricos dos carnavais modernos. Os discentes foram expostos à visão antropológica do Carnaval como ritual de inversão dos papeis sociais e da suspensão das normas de comportamento usuais.

Para a dinâmica do World Café funcionar é fundamental estimular a contribuição de todos, inclusive dos mais inibidos para se expressar oralmente em língua estrangeira. A valorização das diferentes opiniões, das perspectivas múltiplas, é o que torna a rede dialógica viva, pulsante, e permite a conexão, às vezes inusitada, de ideias. Através da escuta atenta dos insights individuais, percebe-se determinados padrões e perspectivas caras aos grupos. A sala foi dividida em dois grupos, cada um com quatro integrantes. A escolha dos grupos coube aos alunos. Foi dado um tempo de 30 minutos para eles responderem as questões propostas e fazerem observações. Depois do tempo determinado, as ideias e descobertas dos dois grupos foram compartilhadas. Os próprios alunos trataram de conectar as ideias de seu grupo com a do outro e também apontar divergências de opiniões entre os integrantes do mesmo grupo.

De acordo com Brown (2002), na metodologia tradicional do World Café existe a figura do "host", hóspede ou anfitrião, responsável pela divisão dos indivíduos em grupos de conversação e também pela definição das questões norteadoras do diálogo. Como mencionado, cada aluno escolheu seu grupo e coube à docente apresentar as questões primordiais. Cada grupo pode contar ainda com um aluno anfitrião, que organiza as discussões de seu grupo e visita os outros grupos para ouvir as demais discussões. Como a turma era pequena, não houve, propriamente, a denominação de um anfitrião do grupo. Naturalmente, o aluno mais extrovertido de cada grupo acabou liderando a discussão e incitando o debate. Os discentes foram orientados a anotar suas ideias através de recursos distintos, como rabiscos, desenhos, palavras-chave, mapas mentais.

Há uma outra versão do World Café, utilizada por David Gurteen (2008), que propôs o termo "Knowledge Café". Em sua proposta, o grupo não é liderado por um anfitrião, tampouco é feito um resumo das discussões para ser compartilhado posteriormente, com os outros grupos. O foco principal aqui seria maximizar o tempo da conversa e do compartilhamento do conhecimento, mais do que sistematizar as ideias levantadas no batepapo.

Depois da dinâmica do World Café é interessante documentar o processo e os resultados obtidos, através de jornais, livros, coletâneas, como o fizemos.

Os dois grupos envolvidos no World Café conseguiram se organizar, dentro do tempo proposto, trocando ideias e percepções sobre o Carnaval. Os pontos de convergência e de divergência sobre a festa foram anotados e serviram para embasar a argumentação na discussão oral. A construção de um discurso crítico sobre o Carnaval, fundamentado em argumentos que foram ponderados coletivamente, facilitou a escrita das redações, que aconteceu em um segundo momento. $\mathrm{O}$ intercâmbio de conhecimento, com as respectivas apresentações de cada grupo, durou em torno de uma hora. Os alunos foram orientados a elaborar as redações em casa, após cuidadosa reflexão sobre os argumentos apresentados no bate-papo. 


\section{ISSN 2707-1642}

\section{Carnaval no World Café}

Uma análise dos temas de interesse dos discentes, recorrentes em sala de aula de Português Língua Estrangeira na UFLA em 2015, permite observar, de imediato, a ideia estereotipada que se tem sobre a cultura brasileira, de um modo geral. Temas como os mencionados - comida brasileira, Carnaval, futebol, corrupção - apontam que os alunos associam cultura a certos aspectos exóticos, turísticos ou políticos do país. Estes aspectos estereotipados são, justamente, aqueles que saltam aos olhos dos discentes estrangeiros, muitas vezes em função do que conhecem da realidade brasileira a partir de seus países, majoritariamente através dos meios de comunicação. Note-se que os alunos disseram "comida brasileira", no singular, apesar de todos, indistintamente, terem relatado que já experimentaram a diversidade da gastronomia brasileira. Tiveram oportunidades distintas para provar o gostinho de nossas comidas através de viagens para eventos nacionais e passeios por diferentes estados. Como sugere DaMatta, a "comida", de fato, é um "dos mais importantes espelhos da cultura brasileira" (1984, p.53).

É curioso notar que, muito embora os discentesjá estivessem residindo no Brasilhá mais de um ano, na ocasião em que cursaram a disciplina, apesar disso foram os temas acima mencionados que lhes vieram à mente. Como os alunos foram convidados a enumerar possíveis temas para uma redação, relacionados à cultura brasileira, pode-se pensar que teriam escolhidos temas por eles considerados familiares. No entanto, a experiência de imersão a qual estão submetidos não parece ter alterado sensivelmente sua percepção da realidade brasileira em geral, e da cultura, em particular.

De qualquer forma, este tipo de experiência faz com que nós, docentes de Português Língua Estrangeira, passemos a refletir sobre nossas práticas cotidianas, a partir de um outro lugar: precisamente aquele iluminado pelas opiniões de nossos alunos. Não seria a partir também desse outro lugar que deveríamos começar a abordar alguns aspectos da cultura brasileira, geralmente silenciados em sala de aula, muito em função do material didático adotado?

A discussão sobre questões aparentemente "menores", banais, quase imperceptíveis para nós, brasileiros, masque encontram ressonância entre os alunos "importados" (para usar a expressão engraçada e muito reveladora de um aluno colombiano), não deveria estar incluída em nossa pauta de ensino?

Entende-se por questões "menores" (não menos importantes), nossos hábitos, nossos modos de ver e de conceber a sociedade, nossas relações interpessoais, nossa linguagem corporal, entre tantas outras possibilidades. Não seria fecundo palmilhar, em sala de aula, o caminho inverso: lançar-se do micro para o macrocosmo? Partir do entendimento das miudezas do cotidiano, em busca de expressões linguísticas e/ou corporais que formariam nosso suculento cadinho cultural poderia ser uma forma interessante de abordar cultura brasileira em sala de aula de Português Língua Estrangeira. Provavelmente esse ca(l)dinho ganharia outro sabor, à luz das impressões certeiras de nossos alunos internacionais

Ampliar a discussão sobre cultura brasileira exige planejamento e coragem para nos encaramos com outros olhos. O próprio entendimento do que é cultura precisa ser bem delineado. Cultura brasileira ou culturas brasileiras? Neste momento utiliza-se o termo no singular, na esteira de Vannucchi (2002), para tratar de aspectos gerais das culturas brasileiras. Assim, a cultura poderia ser concebida como um modo específico de viver, de classificar o mundo, de agir e de interagir em sociedade. Se dentro de um dado grupo há "certo grau de consenso sobre como classificar as coisas", esta forma de classificação ou "sistemas partilhados de significação" são o que se entende por "cultura" (Woodward, 2000, p.41). 


\section{ISSN 2707-1642}

Para Rocha, as "dimensões de uma cultura - da comida à música, da arquitetura à roupa e tanta mais - são pequenos conjuntos padronizados que trazem dentro de si algum tipo de informação sobre quem somos, o que pensamos e fazemos" (2004, p.89). Nesse sentido, a atenção às miudezas é essencial para construímos nossa identidade, também através da linguagem. É "através do processo de construção do significado" que "as pessoas se tornam conscientes de quem elas são, construindo suas identidades sociais ao agir no mundo através da linguagem". (Moita Lopes, 1998, p.304). Assim, pode-se pensar que aprender uma língua estrangeira é, em certa medida, um processo que demanda também a construção de uma outra identidade. Entender e aprofundar-se nas dimensões de uma cultura, portanto, é também aprender a ser, pensar e fazer em outra língua. Portanto, "línguacultura", indissociáveis, permeiam a coletânea surgida a partir das carnavalescas reflexões no Café.

\section{Do Café para o World: a coletânea}

"Olhares Estrangeiros sobre o Carnaval Brasileiro"2 é o resultado do bate-papo promovido pelo World Café. Após a devida correção das redações, sete delas foram reunidas para formar o livro digital, disponível online para leitura e apreciação. Dos oito alunos que cursaram a disciplina Português Língua Estrangeira III, apenas um não autorizou a inclusão de sua redação no livro digital. Todas as redações são precedidas pelas breves biografias e fotos dos discentes participantes. As fotos foram escolhidas pelos próprios alunos. As redações culminaram em atividade avaliativa final. Depois de finalizada, a coletânea foi compartilhada na internet e divulgada no site da universidade, através de uma matéria jornalística, escrita e publicada pela Diretoria de Comunicação (DCOM) da UFLA. ${ }^{3}$

Estes "Olhares" de aprendizagem também muito nos ensinam. Como nos revelam os alunos escritores, "nem todos os brasileiros gostam das coisas do Brasil", "nem todos sabem sambar ou gostam de futebol". E ainda: "para muita gente o Brasil é unicamente sol, praia, música (samba), Carnaval e dança". "O Carnaval que estava na minha mente não era o Carnaval do Brasil". "O Carnaval é uma comunhão entre os povos (de classes sociais distintas)". "Ainda que continue não gostando da cara geral que o Carnaval mostra para o mundo, sei que se essa outra cara (o lado social do Carnaval) fosse mais evidenciada, as pessoas teriam um olhar diferente para esse evento e para o Brasil como um todo".

A proposta pedagógica que fundamentou a criação da coletânea está em franco diálogo com o projeto de extensão "Aquarela Cultural", sob nossa responsabilidade. O objetivo primordial deste projeto, criado em 2015 e em atividade até o momento, é promover o debate intercultural sobre temas diversos, através de atividades como cursos, palestras, minicursos. Posteriormente, a iniciativa surgida em sala de aula da disciplina Português Língua Estrangeira III, ganhou outras dimensões, ao contemplar mais de trinta alunos das turmas iniciais que ficaram interessados em discutir alguns aspectos culturais de seus países. Assim, no mesmo ano de 2015, foi oferecido um curso de extensão, pelos próprios alunos estrangeiros, aberto à comunidade em geral, acadêmica ou não. Nesse curso, os alunos eram livres para escolher o tema de suas apresentações, que poderiam ter até quarenta minutos. Os dez minutos restante, utilizados para perguntas, mostrou-se insuficiente, tamanha foi a recepção e curiosidade dos ouvintes. Dessa forma, viajamos pela América Latina sem sair de Lavras, através de passeios inusitados pela culinária andina, museus guatemaltecos, pontos turísticos peruanos, universidades chilenas, dialetos equatorianos, história do vestuário maia, costumes incas, entre outros. Nessa ocasião, os alunos foram orientados a não abordar a cultura de seus países de forma redutora, simplista ou esquematizada. A única recomendação é para que evitassem visões culturais estereotipadas de seus países pois, como conhecedores de suas realidades, poderiam apresentar ao público nacional e internacional presente, visões e 


\section{ISSN 2707-1642}

aspectos culturais diversificados, matizados e, muitas vezes, desconhecidos por nós, brasileiros.

Conhecer-se através do outro não deixa de ser uma aventura pelo desconhecido, uma viagem de (re) descobertas que pode nos fazer estranhar nosso próprio país, tornando-nos estrangeiros em solo próprio. A passagem para esse outro de mim que se abre à viagem do (auto) descobrimento, seja através do olhar alheio ou do meu próprio olhar enquanto falante de uma língua estrangeira, incita revelações férteis.

A passagem pelo outro, ou para o outro de nós, revela-se através dos "Olhares Estrangeiros", que intitula a coletânea de redações. Em seu sentido etimológico a palavra "estrangeiro" remonta ao latim estranho, ao que vem de fora. Através da leitura destes escritos é possível capturar molduras diferenciadas sobre um mesmo assunto, através de uma ótica de aproximação e de entendimento das diferenças culturais: o que, ao fim, nos torna, todos, muito próximos na celebração e no encontro da (s) língua (s).

\section{Referências}

Brown, J., David \& Isaacs. (2005). The World Café: shaping our futures through conversations that matter. São Francisco, California: Berrett-Koehler Publisher.

Brown, J. (2002). A Resource Guide for the World Café. In: A Resource Guide for Hosting Conversations that Matter at the World Café, p. 1-11. http://www.meadowlark.co/world_cafe_resource_guide.pdf Acessed on 25 nov. 2019.

Damatta, R. (1984). O que faz o Brasil, Brasil? Rio de Janeiro: Rocco.

Gurteen, D. (2008). How to run a knowledge café. http://www.gurteen.com/gurteen/gurteen.nsf/id/kcafe-run. Acessed on 25 de nov. 2019.

Moita Lopes, L. (1998). Discursos de identidade em sala de aula de leitura de L1: a construção de diferença. In: Signorini, I. (Org.). Língua(gem) e Identidade: elementos para umadiscussão no campo aplicado. Campinas, SP: Mercado de Letras.

Rocha, E. \& P. Guimarães. (2004). O que é etnocentrismo? São Paulo: Brasiliense.

Vannucchi, A. (2002). Cultura brasileira: o que é, como se faz. São Paulo: Edições Loyola.

Woodward, K. (2000). Identidade e diferença: uma introdução teórica e conceitual. In: Silva, T. T. (Org.). Identidade e diferença: a perspectiva dos estudos culturais. Petrópolis, RJ: Vozes, p.7-72. 